\title{
Reator em bateladas sequenciais de grânulos aeróbios: estudo da formação dos grânulos e do efeito da duração do ciclo na remoção de carbono, nitrogênio e fósforo de esgoto doméstico
}

\author{
Aerobic granular sludge sequencing batch reactor: study of granule \\ formation and the cycle time effect in the carbon, nitrogen, \\ and phosphorus removal from domestic wastewater
}

Jamile Wagner', Rejane Helena Ribeiro da Costa ${ }^{2}$

口-

\begin{abstract}
RESUMO
Neste trabalho estudou-se a formação de grânulos aeróbios em um reator em bateladas sequenciais alimentado com esgoto doméstico e avaliou-se o desempenho desse reator em relação à remoção de carbono, nitrogênio e fósforo utilizando ciclos operacionais de 3 e 4 h. Após 150 dias de operação, a biomassa do reator era constituída predominantemente por grânulos maduros e compactos, com concentração de sólidos suspensos em torno de 1,5 g.L.-1. O reator apresentou elevada capacidade de remoção de carbono, nitrogênio e fósforo, principalmente quando operado em sucessivos ciclos de $4 \mathrm{~h}$, atingindo uma eficiência média de remoção de demanda química de oxigênio solúvel de $82 \pm 5 \%$, de $\mathrm{NH}_{4}{ }^{+}-\mathrm{N}$ de $69 \pm 19 \%$ e de $\mathrm{PO}_{4}{ }_{4}^{-3} \mathrm{P}$ de $30 \pm 10 \%$.

Palavras-chave: grânulos aeróbios; reator em bateladas sequenciais; remoção de nutrientes; tratamento de esgoto doméstico.
\end{abstract}

\begin{abstract}
In this work, the formation of aerobic granules in a sequencing batch reactor fed with domestic wastewater was studied and the reactor's performance, in terms of carbon, nitrogen, and phosphorus removal, during operational cycles of 3 and $4 \mathrm{~h}$, was evaluated. After 150 days of operation, the reactor's biomass predominantly consisted of compact mature granules, with a suspended solids concentration around 1.5 g.L.'. The reactor presented a high capacity for removing carbon, nitrogen, and phosphorus, mainly when operated in successive cycles of $4 \mathrm{~h}$. Average removal efficiencies of $82 \pm 5 \%$ for soluble chemical oxygen demand, $69 \pm 19 \%$ for $\mathrm{NH}_{4}^{+}-\mathrm{N}$, and $30 \pm 10 \%$ for $\mathrm{PO}_{4}^{3-}-\mathrm{P}$ were obtained.
\end{abstract}

Keywords: aerobic granules; sequencing batch reactor; nutrients removal: domestic wastewater treatment.

\section{INTRODUÇÃO}

As tecnologias desenvolvidas para o tratamento de águas residuárias baseadas na formação de biomassa granular incluem processos de granulação aeróbia e anaeróbia. Dentre os processos de tratamento que aplicam a granulação anaeróbia, os mais conhecidos são os reatores anaeróbios de fluxo ascendente e manta de lodo (do inglês upflow anaerobic sludge blanket UASB). A formação da biomassa na forma de grânulos aeróbios tem sido estudada recentemente em diversos países, utilizando reatores em bateladas sequenciais (RBS) operados em sucessivos ciclos que incluem, principalmente, as seguintes fases: enchimento, aeração, sedimentação e descarte.
A definição do termo "grânulos aeróbios” surgiu após discussões realizadas no primeiro workshop sobre lodo granular aeróbio (1st IWA workshop Aerobic Granular Sludge), que ocorreu na cidade de Munique, Alemanha, em 2004. Segundo de Kreuk et al. (2005), os grânulos aeróbios devem ser entendidos como sendo "agregados de origem microbiana, que não coagulam sob reduzidas condições de cisalhamento hidrodinâmico e que sedimentam significativamente mais rápido que os flocos de lodos ativados". Além disso, como os grânulos aeróbios apresentam uma estrutura compacta, com tamanho variando geralmente entre 0,5 e $2 \mathrm{~mm}$, a resistência à transferência de massa, especialmente à de oxigênio, é maior do

'Doutora em Engenharia Ambiental pela Universidade Federal de Santa Catarina (UFSC) - Florianópolis (SC), Brasil.

2Pós-doutora pela Université Montpellier I, França. Professora Titular da UFSC - Florianópolis (SC), Brasil.

Endereço para correspondência: Jamile Wagner - Campus Universitário Reitor João David Ferreira Lima, Universidade Federal de Santa Catarina - Trindade - $88010-970$ -

Florianópolis (SC), Brasil - E-mail: jamilew@gmail.com

Recebido: 11/01/2012 - Aceito: 27/02/15 - Reg. ABES: 78980 
que no floco de lodo ativado convencional (LIU \& TAY, 2006). Portanto, a limitação da difusão do oxigênio dentro do grânulo permite a existência simultânea de zonas aeróbias, anóxicas e anaeróbias, o que, por sua vez, cria condições ambientais favoráveis para o crescimento de bactérias aeróbias e facultativas, possibilitando a remoção conjunta de carbono, nitrogênio e fósforo (LI et al., 2005; WANG et al., 2009). Segundo de Kreuk (2006), o mecanismo de remoção de nutrientes através de grânulos é semelhante ao utilizado nos sistemas convencionais de lodos ativados, sendo que a principal diferença reside no fato de não ser necessária a utilização de diversos tanques, mas sim, a criação de diferentes zonas no interior do próprio grânulo. Como consequência, essa tecnologia requer uma menor área de implantação em comparação ao sistema de lodos ativados, representando assim uma alternativa promissora para o tratamento de águas residuárias em cidades com disponibilidade de área limitada.

Em relação aos mecanismos de remoção, após a fase de enchimento, a concentração de carbono orgânico no meio líquido é elevada. Esse substrato é completamente difundido para o interior dos grânulos, sendo parcialmente convertido e armazenado na forma de polímeros, como os polihidroxibutiratos (PHB). Em relação ao oxigênio dissolvido (OD), o mesmo tem uma profundidade de penetração muito menor do que o carbono orgânico, em função do rápido consumo de OD pelos organismos autotróficos e heterotróficos localizados na camada externa do grânulo. O nitrito e o nitrato, produzidos pela nitrificação, vão difundir em direção ao centro dos grânulos. Nessa zona, o PHB está disponível para ser usado como fonte de carbono para o processo de desnitrificação. Dessa forma, a remoção de nitrogênio ocorre no interior dos grânulos através do processo de nitrificação e desnitrificação simultâneas (NDS) (DE KREUK \& DE BRUIN, 2004; FIGUEROA et al., 2009).

Entretanto, apesar da granulação aeróbia ter sido extensivamente investigada nos últimos anos, o emprego dessa tecnologia no tratamento de esgotos de origem doméstica tem sido pouco relatado na literatura, citando-se, por exemplo, de Kreuk \& Van Loosdrecht (2006), Ni et al. (2009), Liu et al. (2010) e Wagner \& Costa (2013). Por outro lado, Liu, Moy e Tay (2007), Wang et al. (2009) e Pijuan, Werner e Yuan (2011) avaliaram, em escala laboratorial, o tratamento de esgoto doméstico em reatores inoculados com grânulos pré-cultivados com esgoto sintético. Entretanto, na prática, a utilização de grânulos aeróbios como inóculo em sistemas de larga escala se torna inviável, devido ao grande volume desses reatores (Liu et al., 2010). Assim, para poder aplicar na prática a tecnologia dos grânulos aeróbios é preciso realizar estudos sobre a potencial utilização dessa tecnologia no tratamento de esgoto doméstico, o qual é usualmente caracterizado como sendo de baixa carga orgânica.

Nesse contexto, o presente trabalho teve como objetivo geral estudar a formação de grânulos aeróbios em um RBS alimentado com esgoto doméstico e avaliar o desempenho do reator em relação à remoção de carbono, nitrogênio e fósforo utilizando ciclos operacionais com diferentes tempos de duração.

\section{METODOLOGIA}

\section{Sistema experimental}

O reator em bateladas sequenciais de grânulos aeróbios (RBSG) (Figura 1A) foi construído em coluna cilíndrica de acrílico transparente, apresentando as seguintes dimensões: 2,0 m de altura e 0,09 m de diâmetro interno. A altura útil utilizada para o tratamento foi de $1,73 \mathrm{~m}$, o que corresponde a um volume de $11 \mathrm{~L}$. O sistema era alimentado com esgoto doméstico, captado da rede pública por meio de uma bomba submersa (Schneider, BCS-94) e enviado para um tanque de armazenamento, de onde era então bombeado para o interior do reator nos períodos de enchimento de cada ciclo operacional. A aeração do sistema foi feita utilizando um compressor (Air Pump, EL-100), que enviava ar comprimido através de um difusor circular de membrana (B\&F Dias, ø $230 \mathrm{~mm}$ ) instalado na parte inferior do reator. A vazão de ar foi controlada com o auxílio de um rotâmetro (Omel, OM-0905P4) pré-calibrado. O funcionamento desses equipamentos foi automatizado através de um controlador lógico programável (CLP, Siemens) localizado em um painel de comandos elétricos. Por meio do CLP, foi possível controlar ainda a duração de cada fase do ciclo operacional do reator e o acionamento e desligamento das bombas de entrada/saída de esgoto e do compressor de ar. Na Figura 1B apresenta-se um esquema do sistema experimental.

\section{Operação do reator}

O reator foi inoculado com 3,5 L de lodo ativado proveniente de uma estação de tratamento de esgoto doméstico. O inóculo apresentava uma concentração de sólidos suspensos totais (SST) de 4,5 g.L-1 e um índice volumétrico de lodo $\left(\mathrm{IVL}_{30}\right)$ de $187 \mathrm{~mL} \cdot \mathrm{g}^{-1}$. Após a inoculação, o RBSG foi inicialmente operado em sucessivos ciclos de $3 \mathrm{~h}$, compreendendo 0,5 min de enchimento, 164 min de aeração, 15 min de sedimentação e 0,5 min de retirada do efluente tratado. A fim de melhorar o desempenho do reator, após 88 dias de operação a duração do ciclo foi aumentada para $4 \mathrm{~h}$, compreendendo 0,5 min de enchimento, $224 \mathrm{~min}$ de aeração, 15 min de sedimentação e 0,5 min de retirada do efluente tratado. A escolha de se iniciar a operação do reator com ciclos de $3 \mathrm{~h}$ e tempo de sedimentação de $15 \mathrm{~min}$. foi baseada no estudo de Ni et al. (2009). Esses autores conseguiram formar grânulos aeróbios em um RBS utilizando esgoto doméstico de baixa concentração. Além disso, a utilização de ciclos de curta duração é uma maneira eficaz de aumentar a carga orgânica aplicada ao sistema, quando se utiliza esgoto de baixa concentração, como o esgoto doméstico.

O volume de enchimento foi de 4,4 L, ou seja, a cada ciclo o percentual de troca volumétrica $\left(\mathrm{V}_{\text {enchimento }} / \mathrm{V}_{\text {reator }}\right)$ foi de $40 \%$, resultando em 35,1 L e 26,4 L de esgoto tratados diariamente, para os ciclos de 3 e $4 \mathrm{~h}$, respectivamente. O RBSG foi operado em temperatura ambiente, sem controle de $\mathrm{pH}$. A vazão de ar aplicada foi sempre maior do que 243 L.h ${ }^{-1}$, o que corresponde a uma velocidade superficial ascensional de 
ar de $1,1 \mathrm{~cm} \cdot \mathrm{s}^{-1}$. Esse valor foi adotado com base nos estudos de McSwain Sturm e Irvine (2008), que concluíram que os grânulos aeróbios não são estáveis quando são aplicadas velocidades superficiais ascensionais de ar menores do que $1,0 \mathrm{~cm} \cdot \mathrm{s}^{-1}$, em sistemas onde a força de cisalhamento é controlada somente pela taxa de aeração. Além disso, periodicamente as paredes do reator eram limpas a fim de impedir a formação de biofilme. Esse procedimento foi adotado tendo em vista que os microrganismos presentes no biofilme podem entrar em competição com os grânulos pelo substrato. Quando o crescimento do biofilme é limitado através da limpeza das paredes do reator, o crescimento dos microrganismos na forma de grânulos se torna mais vantajoso (MORGENROTH et al., 1997). Na Tabela 1 é apresentada uma síntese das condições operacionais estabelecidas e das cargas aplicadas durante o tempo de operação.

\section{Análises laboratoriais}

A fim de monitorar o desempenho do reator, amostras do afluente bruto (entrada do reator), licor misto e efluente tratado (saída do reator) foram coletadas duas vezes por semana. As análises físico-químicas foram feitas segundo as metodologias recomendadas pelo Standard Methods (APHA, 2005). As variáveis analisadas foram: oxigênio dissolvido (OD), temperatura, $\mathrm{pH}$, demanda química de oxigênio solúvel ( $\mathrm{DQO}_{\mathrm{s}}$ ), nitrogênio amoniacal $\left(\mathrm{NH}_{4}^{+}-\mathrm{N}\right)$, nitrito $\left(\mathrm{NO}_{2}^{-}-\mathrm{N}\right)$, nitrato $\left(\mathrm{NO}_{3}^{-}-\mathrm{N}\right)$, fosfato
$\left(\mathrm{PO}_{4}^{3-}-\mathrm{P}\right)$ sólidos suspensos totais (SST) e sólidos suspensos voláteis (SSV). O índice volumétrico do lodo (IVL) foi determinado seguindo a metodologia proposta por Schwarzenbeck, Erley e Wilderer (2004), na qual o IVL é calculado para diferentes tempos de sedimentação, e não apenas após 30 minutos, como no método tradicional. Neste estudo, escolheu-se determinar o volume do lodo após 10, 15 e 30 min de sedimentação em uma proveta graduada de 1 L. O IVL foi calculado usando a Equação 1.

Tabela 1 - Características do esgoto doméstico e das cargas aplicadas durante o tempo de operação do reator em bateladas sequenciais de grânulos aeróbios.

\begin{tabular}{|c|c|c|}
\hline Variáveis & Ciclo $3 \mathrm{~h}$ & Ciclo $4 \mathrm{~h}$ \\
\hline Duração (dias) & 88 & 83 \\
\hline Carga orgânica $\left(\mathrm{kg} \mathrm{DQO}_{\mathrm{s}} \mathrm{m}^{-3} \cdot \mathrm{d}^{-1}\right)$ & $1,40 \pm 0,43(16)^{*}$ & $1,00 \pm 0,23(20)^{*}$ \\
\hline Carga nitrogenada $\left(\mathrm{kg} \mathrm{NH}_{4}{ }^{+}-\mathrm{N} \cdot \mathrm{m}^{3} \cdot \mathrm{d}^{-1}\right)$ & $0,29 \pm 0,04(16)^{*}$ & $0,20 \pm 0,01(20)^{*}$ \\
\hline Carga de fósforo ( $\mathrm{kg} \mathrm{PO}_{4}^{3-} \cdot \mathrm{P}^{\left.-\mathrm{m}^{-3} \cdot \mathrm{d}^{-1}\right)}$ & $0,03 \pm 0,01(16)^{*}$ & $0,02 \pm 0,01(20) *$ \\
\hline Tempo de retenção hidráulica (h) & 7,5 & 10 \\
\hline \multicolumn{3}{|l|}{ Duração da fase (min) } \\
\hline Enchimento & 0,5 & 0,5 \\
\hline Aeração & 164 & 224 \\
\hline Sedimentação & 15 & 15 \\
\hline Retirada & 0,5 & 0,5 \\
\hline
\end{tabular}

DQO : demanda química de oxigênio solúvel; *média土desvio padrão (número de dados).
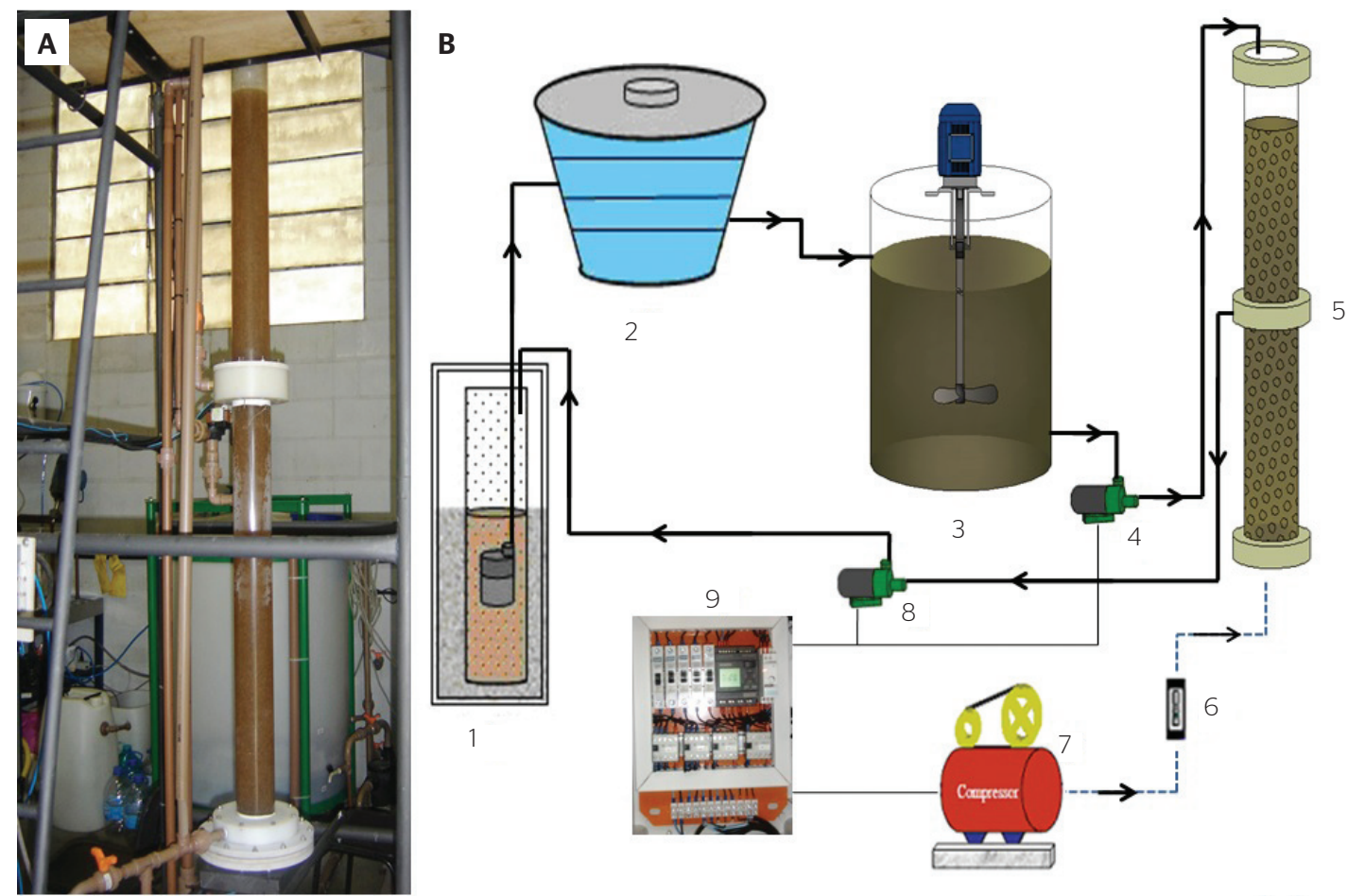

1: rede pública de esgotos; 2: tanque de passagem; 3: tanque de armazenamento com misturador; 4: bomba de alimentação do reator; 5: reator em bateladas sequenciais com grânulos aeróbios; 6: rotâmetro; 7: compressor de ar; 8: bomba para retirada do efluente; 9: painel de comandos elétricos.

Figura 1 - Foto do reator (A) e ilustração esquemática do sistema experimental (B). 
$I V L_{t}=\frac{V L S \times 1000}{S S T}$

onde,

IVL =índice volumétrico do lodo $\left(\mathrm{mL} \cdot \mathrm{g}^{-1}\right)$

$\mathrm{t}$ =tempo de sedimentação (min)

VLS =volume de lodo sedimentado (mL.L $\left.\mathrm{L}^{-1}\right)$

SST =concentração de sólidos suspensos totais da amostra $\left(\mathrm{mg} . \mathrm{L}^{-1}\right)$

O acompanhamento da formação e da morfologia dos grânulos foi realizado por meio da utilização de microscópio ótico (Olympus BX-40). O diâmetro dos grânulos foi medido com o auxílio de uma lente ocular com escala micrométrica. Fotos foram tiradas utilizando máquina fotográfica digital (Sony Cybershot DSC - P93).

\section{Cálculos realizados}

A eficiência de remoção para as variáveis DQO, $\mathrm{NH}_{4}{ }^{+} \mathrm{N}$ (nitrificação), nitrogênio total (Nt) e $\mathrm{PO}_{4}^{3--} \mathrm{P}$, foi calculada a partir da Equação 2.

$E=\left(\frac{S_{A}-S_{E}}{S_{A}}\right) \cdot 100$

onde,

$\mathrm{E}=$ eficiência de remoção (\%)

$\mathrm{S}_{\mathrm{A}}=$ concentração do substrato no afluente bruto (mg. $\left.\mathrm{L}^{-1}\right)$

$\mathrm{S}_{\mathrm{E}}=$ concentração do substrato no efluente tratado $\left(\mathrm{mg} \cdot \mathrm{L}^{-1}\right)$

A eficiência do processo de desnitrificação foi calculada utilizando-se a Equação 3.

$E_{D N}=\left(\frac{\left(\left(N H_{4}^{+}-N\right)_{A}-\left(N H_{4}^{+}-N\right)_{E}\right)-\left(N O_{X}-N\right)_{E}}{\left(\left(N H_{4}^{+}-N\right)_{A}-\left(N H_{4}^{+}-N\right)_{E}\right)}\right) \cdot 100$

onde,

$\mathrm{E}_{\mathrm{DN}}=$ eficiência de desnitrificação (\%)

$\left(\mathrm{NH}_{4}^{+}-\mathrm{N}\right)_{\mathrm{A}}=$ concentração de nitrogênio amoniacal no afluente bruto $\left(\mathrm{mg} . \mathrm{L}^{-1}\right)$

$\left(\mathrm{NH}_{4}{ }^{+}-\mathrm{N}\right)_{\mathrm{E}}=$ concentração de nitrogênio amoniacal no efluente tratado (mg.L $\left.\mathrm{L}^{-1}\right)$

$\left(\mathrm{NO}_{\mathrm{X}}-\mathrm{N}\right)_{\mathrm{E}}=$ concentração de nitrito e nitrato no efluente $\left(\mathrm{mg} \cdot \mathrm{L}^{-1}\right)$

O tempo de retenção hidráulica foi calculado a partir da Equação 4.

$T R H=\frac{V_{u}}{Q_{d}}$

onde,

TRH =tempo de retenção hidráulica (dias)

$\mathrm{Q}_{\mathrm{d}}=$ vazão diária de esgoto $\left(\mathrm{m}^{3} \cdot \mathrm{dia}^{-1}\right)$

$\mathrm{V}_{\mathrm{u}}=$ volume útil do reator $\left(\mathrm{m}^{3}\right)$
O tempo de retenção de sólidos (TRS - idade do lodo) foi calculado a partir da Equação 5 (LIU \& TAY, 2007a).

$\Theta=\frac{X_{S S V} V_{u}}{\left(X_{d} V_{d}+X_{e} V_{e}\right) / t_{c}}$

onde,

$\theta$ =tempo de retenção de sólidos (d)

$\mathrm{X}_{\mathrm{ssv}}=$ concentração de sólidos suspensos voláteis no reator $\left(\mathrm{mg} . \mathrm{L}^{-1} \mathrm{de} S \mathrm{SS}\right)$

$\mathrm{V}_{\mathrm{u}}=$ volume útil do reator $(\mathrm{L})$

$\mathrm{X}_{\mathrm{e}}=$ concentração de sólidos suspensos voláteis no efluente tratado (mg.L-1 de SSV)

$\mathrm{V}_{\mathrm{e}}$ =volume de efluente tratado descartado do reator $(\mathrm{L})$

$\mathrm{X}_{\mathrm{d}}=$ concentração de biomassa manualmente descartada (mg.L ${ }^{-1}$ de SSV)

$\mathrm{V}_{\mathrm{e}}=$ volume de biomassa descartada manualmente (L)

$\mathrm{t}_{\mathrm{C}}=$ tempo de duração do ciclo $(\mathrm{d})$

Uma vez que não houve descarga manual de lodo durante o funcionamento do reator, a Equação 5 pode ser simplificada na Equação 6 .

$\Theta=\frac{X_{S S V} V_{u}}{\left(X_{e} V_{e}\right) / t_{c}}$

\section{RESULTADOS E DISCUSSÃO}

\section{Características da biomassa granular}

A evolução da formação dos grânulos ao longo do período de operação pode ser visualizada na Figura 2 (2A a 2E - ciclo de 3 h; $2 \mathrm{~F}$ a $2 \mathrm{I}$ - ciclo de 4 h). O lodo utilizado como inóculo (Figura 2A) era formado majoritariamente por flocos, os quais apresentavam uma estrutura morfológica bastante irregular. Após 14 dias de operação (Figura 2B) observou-se o início da aglutinação dos microrganismos para a formação dos grânulos. Os primeiros grânulos começaram a aparecer com 28 dias (Figura 2C), mas os mesmos apresentavam uma superfície bastante filamentosa. A partir de 56 dias (Figuras 2D e 2E) os grânulos se tornaram mais densos, apresentando uma estrutura mais regular e esférica. Entretanto, nesse período, a presença de flocos no reator ainda era dominante. Com o passar do tempo, o número de grânulos, bem como o diâmetro dos mesmos, foi aumentando gradativamente (Figuras 2F a 2H). Com 150 dias de operação (Figura 2I), a biomassa do reator era formada principalmente por grânulos maduros e compactos, com diâmetros variando entre 0,3 e 1,3 mm e diâmetro médio de 0,5 mm. Nesse período, foi possível observar a presença de apenas alguns flocos. Esses resultados estão de acordo com De Kreuk et al. (2005), que recomendam que o tamanho mínimo dos grânulos seja em torno de $0,2 \mathrm{~mm}$, a fim de poder separá-los corretamente dos flocos durante a fase de sedimentação. Além disso, a partir da Figura 2, pode-se perceber que a formação dos grânulos é um processo gradual que segue três estágios consecutivos: aclimatação do lodo, agregação do lodo e maturação dos grânulos (WANG et al., 2005). 
口-

Na Tabela 2 é apresentada uma comparação entre os resultados obtidos em estudos sobre o processo de granulação aeróbia em RBS utilizando esgoto doméstico e sintético. Esses resultados indicam que o processo de formação dos grânulos aeróbios utilizando esgoto doméstico requer mais tempo do que os sistemas que utilizam esgoto sintético. De acordo com
Liu et al. (2010), os grânulos aeróbios cultivados com esgotos sintéticos usualmente levam de 2 a 4 semanas para se formarem e de 1 a 2 meses para alcançar o estado estacionário em reatores de escala laboratorial. Esses autores sugerem que isso pode ser explicado pelo fato de que os esgotos reais apresentam uma elevada flutuação dos componentes, principalmente de
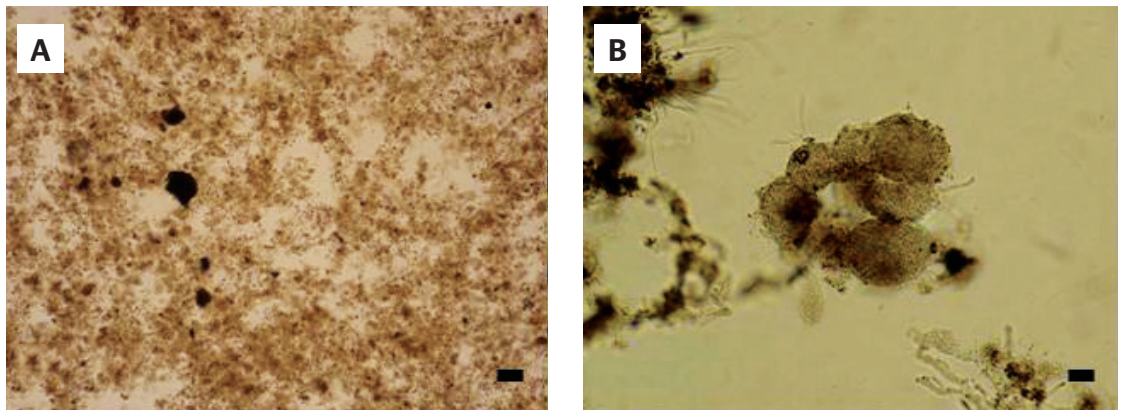

C
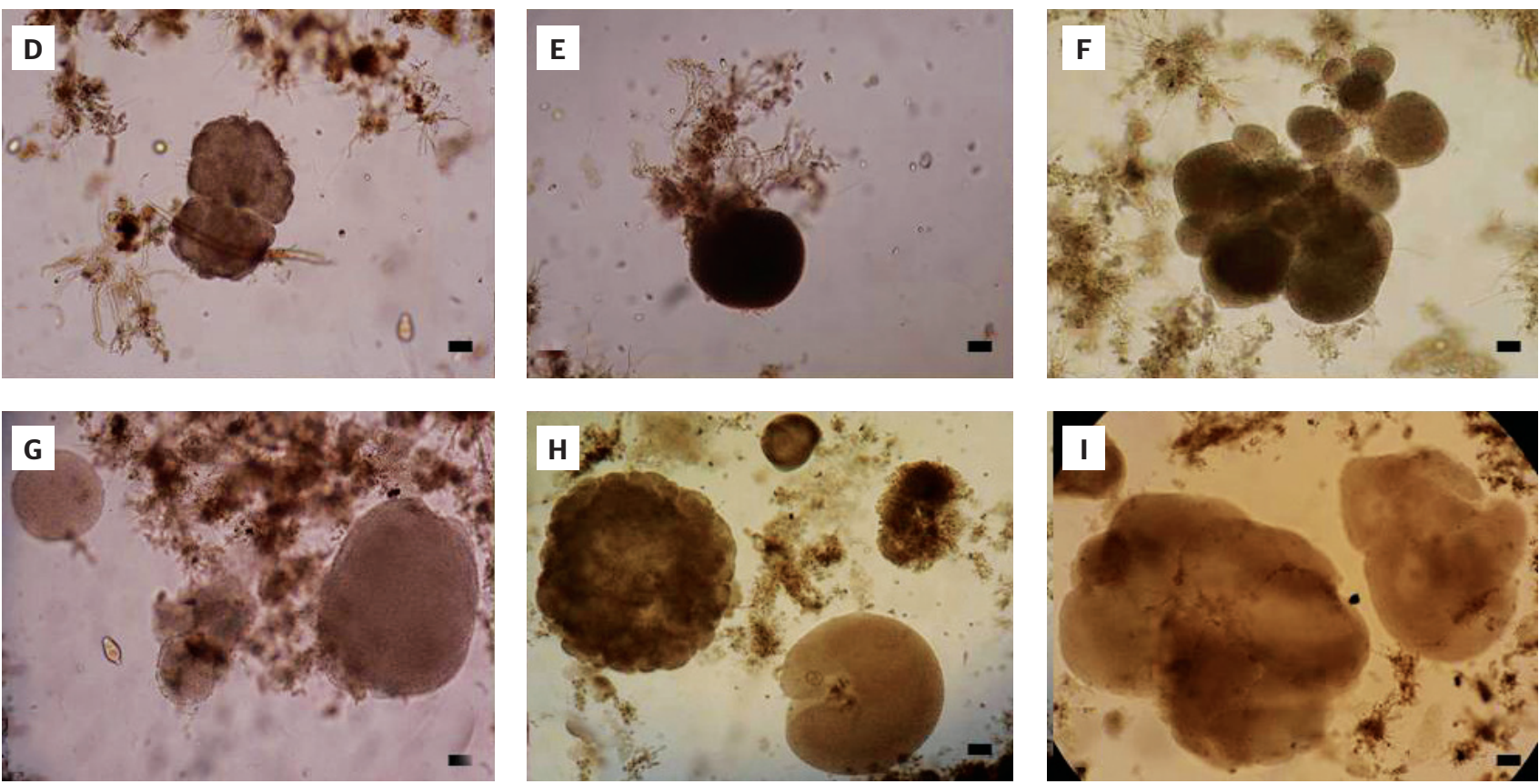

Figura 2 - Evolução da formação dos grânulos no reator (A) inóculo; (B) 14 dias; (C) 28 dias; (D) 56 dias; (E) 70 dias; (F) 99 dias; (G) 114 dias; (H) 121 dias; e (I) 150 dias. Barra=0,1 mm.

Tabela 2 - Comparação entre estudos sobre a formação de grânulos aeróbios utilizando esgoto doméstico e sintético.

\begin{tabular}{|c|c|c|c|c|c|}
\hline \multirow[b]{2}{*}{ Referência } & \multirow[b]{2}{*}{ Afluente } & \multicolumn{2}{|c|}{ Concentração de afluente bruto } & \multirow[b]{2}{*}{$\begin{array}{c}\text { Tempo de } \\
\text { granulação (d) }\end{array}$} & \multirow[b]{2}{*}{$\begin{array}{l}\text { Diâmetro dos } \\
\text { grânulos (mm) }\end{array}$} \\
\hline & & $\begin{array}{c}\mathrm{DQO}_{\mathrm{s}} \\
\left(\mathrm{mg} \cdot \mathrm{L}^{-1}\right)\end{array}$ & $\begin{array}{l}\mathrm{NH}_{4}^{+}-\mathrm{N} \\
\left(\mathrm{mg}^{\left.-\mathrm{L}^{-1}\right)}\right.\end{array}$ & & \\
\hline Este estudo & Esgoto doméstico & $191-602$ & $73-112$ & $\sim 150$ & $0,3-1,3$ \\
\hline De Kreuk \& Van Loosdrecht (2006) & Esgoto doméstico & $280^{*}$ & $57^{*}$ & 36 & $1,1^{*}$ \\
\hline Liu et al. (2010) & Esgoto doméstico e industrial & $250-1800$ & 39-93 & 400 & $0,35^{*}$ \\
\hline Morgenroth et al. (1997) & Esgoto sintético & $400^{*}$ & $22^{*}$ & 70 & $2,35^{\star}$ \\
\hline Wang et al. (2007) & Esgoto sintético & $920^{*}$ & - & 42 & $1,0-2,0$ \\
\hline Jungles et al. (2011) & Esgoto sintético & $600-2500$ & $35-130$ & 63 & $3,5^{*}$ \\
\hline
\end{tabular}

DQO : demanda química de oxigênio solúvel; *valor médio. 
DQO, o que leva a uma condição ambiental instável e resulta em um processo de granulação mais lento do que comparado com os esgotos sintéticos.

Na Figura 3 está apresentada a evolução da concentração de SST no reator, do TRS e da sedimentabilidade do lodo ao longo do tempo de operação. Após a inoculação, a concentração inicial de SST no reator era de 1,6 g.L $\mathrm{L}^{-1}$ (dado não apresentado). Em função do baixo tempo de sedimentação, o lodo com pior sedimentabilidade foi "lavado" do reator, saindo com o efluente tratado, e somente as partículas com boa sedimentabilidade ficaram retidas no reator. Como resultado, a perda da biomassa causou uma severa diminuição na concentração de SST, alcançando 0,2 g.L.-1 aos 7 dias de operação. Devido à formação dos grânulos (Figura 2), o TRS e a concentração de SST aumentaram gradualmente, estabilizando-se, respectivamente, em torno de 4,7 d e 1,5 g.L $\mathrm{L}^{-1}$ após 60 dias. Operando o reator com ciclos de duração de $4 \mathrm{~h}$, observou-se que o TRS aumentou ainda mais, atingindo um valor médio de $12,5 \mathrm{~d}$, enquanto que a concentração de biomassa manteve-se em torno de 1,5 g.L.-1 (Figura 3A).

O lodo utilizado como inóculo apresentava um valor de $\mathrm{IVL}_{30}$ igual a $187 \mathrm{~mL} \cdot \mathrm{g}^{-1}$. Com 7 dias de operação (Figura 3B), esse valor caiu para $130 \mathrm{~mL} \cdot \mathrm{g}^{-1}$, comprovando a observação de que a biomassa com pior sedimentabilidade foi "lavada" do reator. Ao longo da evolução da formação dos grânulos, $\mathrm{o} \mathrm{IVL}_{30}$ diminuiu gradualmente, estabilizando-se em torno de $53 \mathrm{~mL} \cdot \mathrm{g}^{-1}$, após 100 dias de operação. De acordo com Von Sperling (2002) quanto maior o valor do $\mathrm{IVL}_{30}$, pior a sedimentabilidade do lodo. Portanto, pode-se concluir que os grânulos maduros obtidos nesta pesquisa apresentaram uma melhor sedimentabilidade quando comparada à do inóculo. Pode-se notar ainda que a concentração de biomassa no reator foi inversamente proporcional à sedimentabilidade da mesma, ou seja, quanto maior a concentração de biomassa, maior a eficiência da sedimentação e menor o valor de IVL. Essa mesma constatação foi observada por Schwarzenbeck, Borges e Wilderer (2005).
Por apresentarem elevada capacidade de sedimentação, a separação entre a biomassa e o efluente tratado nos sistemas de grânulos aeróbios é bastante eficiente, gerando um sobrenadante clarificado, geralmente livre de sólidos em suspensão. Entretanto, de acordo com Schwarzenbeck, Borges e Wilderer (2005), durante o período de arranque do reator e por razões de segurança, no caso da desintegração dos grânulos, um sistema de retenção da biomassa deve ser adicionado em uma etapa subsequente ao reator granular. Esses autores consideram que um processo de separação sólido/líquido é suficiente, desde que a eficiência de remoção biológica do reator seja elevada.

A partir da Figura 3B, percebe-se que houve diferença entre os valores de $I V L_{10}, I V L_{15}$ e IVL $L_{30}$ durante todo o período de operação do reator. No entanto, com a formação dos grânulos, essa diferença diminuiu, e a relação $\mathrm{IVL}_{30} / \mathrm{IVL}_{10}$ ficou próxima de $90 \%$ após 140 dias de operação. De acordo com De Kreuk et al. (2005), a relação entre o $I_{V L}$ e o IVL $L_{10}$ é considerada com sendo um bom indicador sobre a formação dos grânulos, devido à excelente sedimentabilidade dos mesmos. Liu e Tay (2007b) consideram que o processo de granulação está completo quando a diferença entre $\mathrm{IVL}_{10}$ e o $\mathrm{IVL}_{30}$ está próxima de $10 \%$, ou seja, $\mathrm{IVL}_{30} / \mathrm{IVL}_{10} \mathrm{em}$ torno de $90 \%$. Dessa forma, pode-se concluir que a partir dos 140 dias de operação o processo de granulação no reator estava completo, o que corrobora a visualização microscópica apresentada na Figura 2I.

\section{DESEMPENHO DO REATOR}

\section{Monitoramento do oxigênio dissolvido, $\mathrm{pH}$ e temperatura}

$\mathrm{O}$ monitoramento do reator em termos de $\mathrm{OD}, \mathrm{pH}$ e temperatura estão apresentados na Tabela 3. Os valores médios de OD durante a fase aerada foram de 8,3 e 7,5 mg. $\mathrm{L}^{-1}$ para os ciclos de 3 e $4 \mathrm{~h}$, respectivamente.
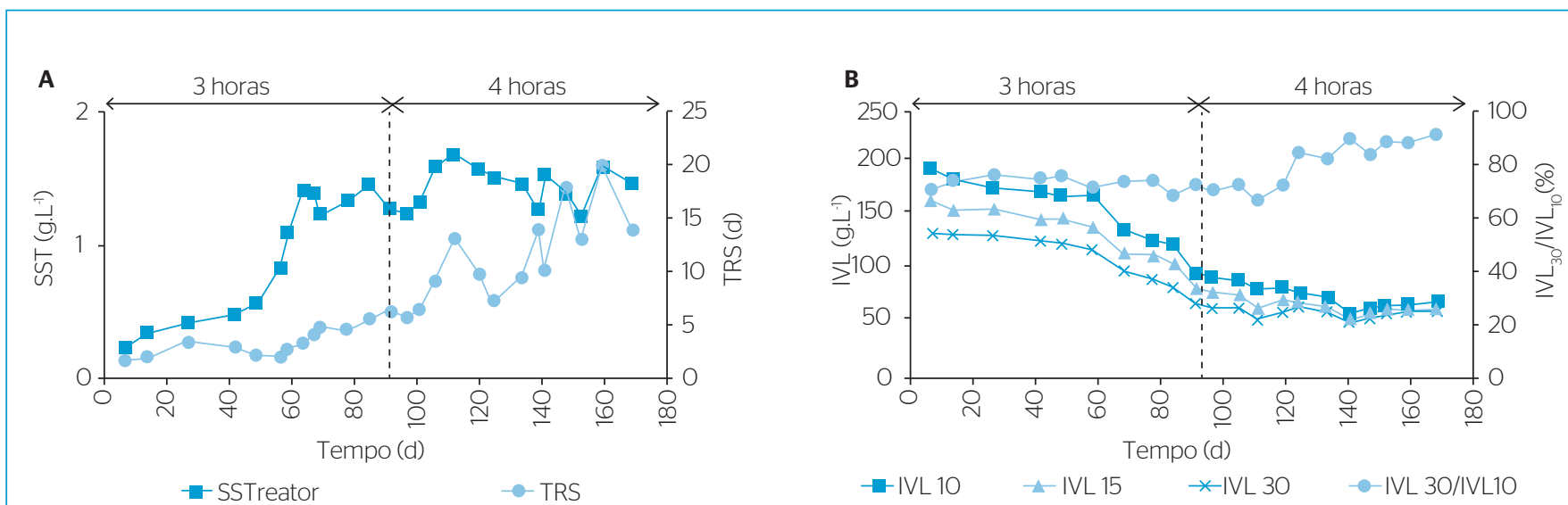

SST: sólidos suspensos totais; TRS: tempo de retenção de sólidos; IVL: índice volumétrico de lodo; IVL $\mathrm{L}_{30} / \mathrm{IVL}_{10}$ : relação do IVL após 30 min de sedimentação e após 10 min de sedimentação.

Figura 3 - Evolução (A) do tempo de retenção de sólidos e da concentração de sólidos suspensos totais no reator, e (B) da sedimentabilidade do lodo (em termos do índice volumétrico do lodo) ao longo do tempo de operação. 
A menor concentração de OD durante os ciclos de $4 \mathrm{~h}$ pode estar relacionada com a maior concentração de SST no reator observada nesse período (Figura 3A). Dessa forma, houve um maior consumo de OD por parte dos microrganismos no processo de metabolização do substrato. Os valores de OD observados estão todos dentro do recomendado para a oxidação da matéria orgânica carbonácea e também para a ocorrência do processo de nitrificação, de acordo com Metcalf \& Eddy Inc. (2003). Por outro lado, os valores de OD encontram-se acima do admitido para a ocorrência da desnitrificação. Entretanto, a concentração de OD foi medida no meio líquido, não representando a real concentração de OD no interior dos grânulos. De maneira geral, nota-se que os valores de OD foram bastante elevados, o que por sua vez pode gerar um alto consumo de energia pelo sistema. No entanto, esses valores de OD foram resultantes da vazão de ar aplicada a fim de se obter o cisalhamento adequado para a formação dos grânulos, conforme recomendado por McSwain Sturm e Irvine (2008).

Em relação ao pH, valores médios de 8,0 e 8,3 para os ciclos de 3 e $4 \mathrm{~h}$, respectivamente, foram registrados no reator. Esses valores estão dentro do recomendado para a oxidação da matéria orgânica carbonácea, de acordo com Metcalf \& Eddy Inc. (2003). No entanto, o pH médio para os ciclos de $4 \mathrm{~h}$ está um pouco fora da faixa ideal para a ocorrência de nitrificação, que segundo USEPA (2010) é de 7,4 a 8,0.

As temperaturas médias para os ciclos de 3 e $4 \mathrm{~h}$ foram, respectivamente, de 18 e $21^{\circ} \mathrm{C}$, estando dento da faixa recomendada para a oxidação do material orgânico, conforme Sant’Anna Jr. (2010). Entretanto, esses valores se encontram fora da faixa de temperatura ótima de crescimento das bactérias nitrificantes, que, segundo Bernet e Spérandio (2009), é entre 28 e $36^{\circ} \mathrm{C}$.

\section{Remoção de carbono, nitrogênio e fósforo}

Os resultados obtidos com o RBSG em relação à remoção da matéria carbonácea e nitrogenada para os ciclos de 3 e 4 h estão apresentados nas Figuras 4 e 5, respectivamente. Durante os primeiros 50 dias de operação o processo não estava estável, em virtude da necessidade de aclimatação do lodo inoculado às novas condições operacionais e também devido à baixa concentração de sólidos no reator durante esse período, conforme apresentado na Figura 3A. Após esse período inicial, o desempenho do reator aumentou continuamente, atingindo uma eficiência de remoção média de $\mathrm{DQO}_{\mathrm{s}}$ de $78 \pm 9 \%$ e de $\mathrm{NH}_{4}{ }^{+}-\mathrm{N}$ de $23 \pm 4 \%$, para os ciclos de $3 \mathrm{~h}$. Esse aumento na eficiência de remoção também está relacionado com o aparecimento dos grânulos no reator (Figura 2D). Em relação à concentração de $\mathrm{DQO}_{\mathrm{s}}$

Tabela 3- Resultados obtidos para oxigênio dissolvido, $\mathrm{pH}$ e temperatura do reator.

\begin{tabular}{l|c|c}
\hline Variável & Ciclo $3 \mathrm{~h}^{*}$ & Ciclo $4 \mathrm{~h}^{*}$ \\
\hline Oxigênio dissolvido $\left(\mathrm{mg} \mathrm{L}^{-1}\right)$ & $8,3 \pm 1,3(29)$ & $7,5 \pm 1,8(70)$ \\
\hline $\mathrm{pH}$ & $8,0 \pm 0,2(42)$ & $8,3 \pm 0,2(70)$ \\
\hline Temperatura (ㅇ) & $18,0 \pm 3,0(42)$ & $21,0 \pm 2,0(70)$ \\
\hline
\end{tabular}

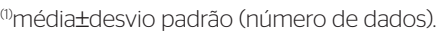

e $\mathrm{NH}_{4}^{+}-\mathrm{N}$ no efluente tratado, nesse mesmo período, obteve-se valores médios de 85 e $68 \mathrm{mg} . \mathrm{L}^{-1}$, respectivamente. Operando o reator com ciclos de $4 \mathrm{~h}$, houve uma diminuição da carga aplicada e um aumento da duração da fase aeróbia, com isso a eficiência média de remoção de $\mathrm{DQO}_{\mathrm{s}} \mathrm{e}$ $\mathrm{NH}_{4}^{+}-\mathrm{N}$ aumentou para $82 \pm 5 \%$ e $69 \pm 19 \%$, respectivamente. Já a concentração média de $\mathrm{DQO}_{\mathrm{s}}$ do efluente diminuiu para $72 \mathrm{mg} . \mathrm{L}^{-1}$ e a de $\mathrm{NH}_{4}{ }^{+} \mathrm{N}$ para $26 \mathrm{mg} \cdot \mathrm{L}^{-1}$. Além disso, o melhor desempenho de remoção de $\mathrm{NH}_{4}^{+}-\mathrm{N}$ com ciclos de 4 h está relacionado com a maior idade de lodo observada no reator neste período (Figura 3A), o que permitiu o enriquecimento de bactérias de crescimento lento, como os organismos nitrificantes.

Na Tabela 4 estão apresentados os resultados do desempenho do reator do presente estudo e de RBSG utilizados no tratamento de esgoto doméstico em ciclos operacionais com diferentes tempos de duração. De maneira geral, esses resultados indicam que a remoção de $\mathrm{NH}_{4}{ }^{+}-\mathrm{N}$ é fortemente afetada pela duração do ciclo. Essa constatação está de acordo com os resultados encontrados por Tay, Yang e Liu (2002), os quais investigaram a formação de grânulos nitrificantes em ciclos com diferentes durações e reportaram

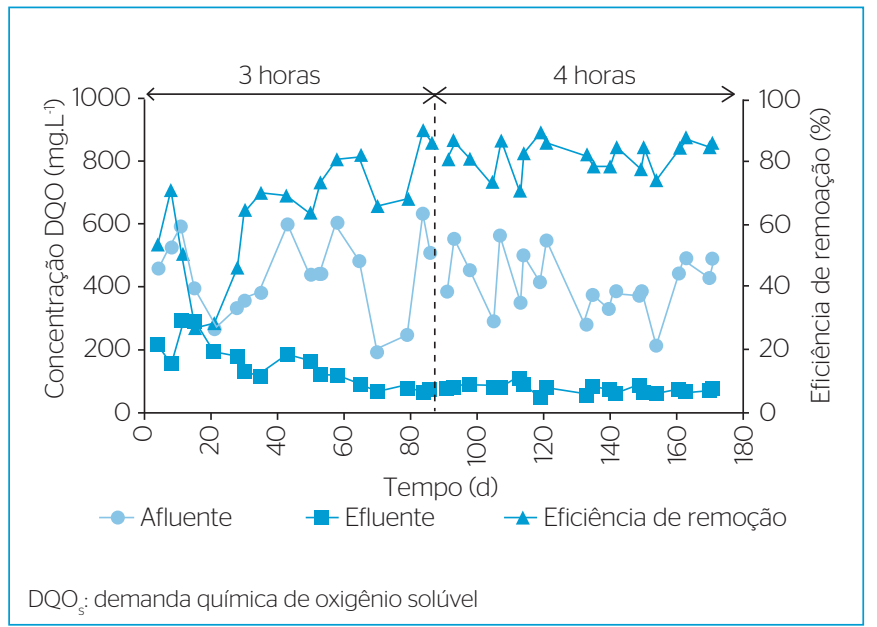

Figura 4 - Comportamento da concentração de demanda química de oxigênio solúvel afluente e efluente e a respectiva eficiência de remoção ao longo do tempo de operação.

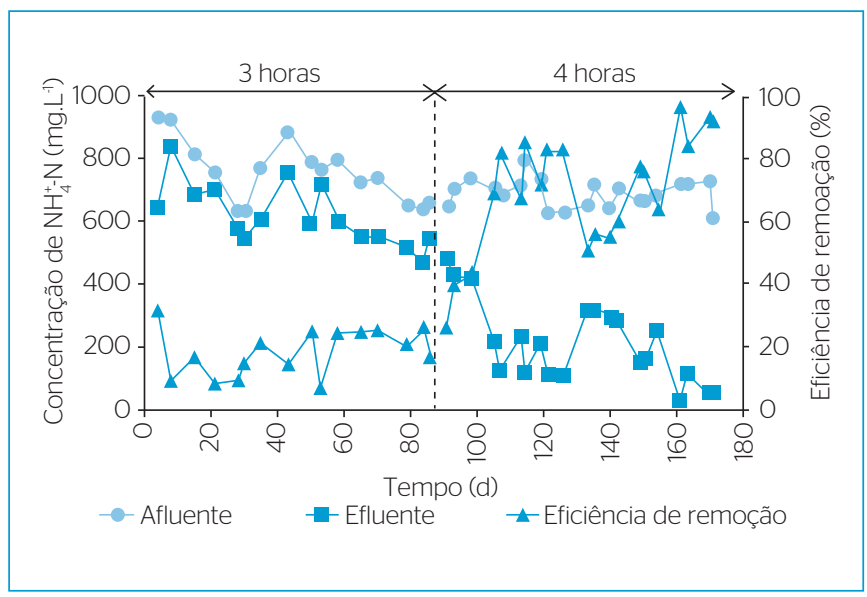

Figura 5 - Comportamento da concentração de $\mathrm{NH}_{4}{ }_{4}^{+} \mathrm{N}$ afluente e efluente e a respectiva eficiência de remoção ao longo do tempo de operação. 
que com ciclos de $3 \mathrm{~h}$ o lodo foi completamente "lavado" do reator, impedindo a formação de grânulos nitrificantes. Por outro lado, analisando a Tabela 4 nota-se que Ni et al. (2009) obtiveram os melhores resultados para remoção de $\mathrm{NH}_{4}^{+}-\mathrm{N}$, mesmo com ciclos de $3 \mathrm{~h}$ de duração. Entretanto, esses autores empregaram, durante o primeiro mês de operação, ciclos de $4 \mathrm{~h}$, o que pode ter favorecido o crescimento dos organismos nitrificantes.

De acordo com Wang \& Liu (2008), a duração do ciclo está ligada diretamente com a frequência com que os sólidos são "lavados" do reator através da fase de retirada do efluente tratado, e está relacionada com o tempo de retenção hidráulica (TRH) e o TRS. Dessa forma, com o aumento do ciclo de 3 para 4 h, o TRH do reator aumentou de 7,5 para $10 \mathrm{~h}$, respectivamente, diminuindo a frequência com que os sólidos eram "lavados" do reator, aumentando a idade do lodo e favorecendo o desenvolvimento de bactérias nitrificantes no interior dos grânulos. Além disso, segundo Metcalf \& Eddy Inc. (2003), comparado com os microrganismos heterotróficos responsáveis pela estabilização da matéria carbonácea, o crescimento das bactérias nitrificantes é lento, mesmo nas condições ótimas. Assim, em um sistema de tratamento biológico em que se objetiva a nitrificação, o tempo de residência celular deve ser tal que propicie o desenvolvimento das bactérias nitrificantes, antes que elas sejam "lavadas" do sistema.

De maneira geral, ciclos de curta duração podem impedir o crescimento de flocos, dado que o material suspenso é frequentemente "lavado" do sistema. Por outro lado, se a duração do ciclo é muito curta, a perda de biomassa não pode ser compensada pelo crescimento bacteriano. Dessa forma, o ciclo deve ser suficientemente curto para que o lodo que sedimenta mal seja "lavado" do reator, e ainda suficientemente longo para que haja o crescimento e o acúmulo microbiano (LIU \& TAY, 2004). Dessa forma, com o aumento da duração do ciclo observou-se um aumento da idade do lodo e consequentemente uma melhora significativa no desempenho do reator, em termos de remoção de $\mathrm{NH}_{4}^{+}-\mathrm{N}$.

$\mathrm{Na}$ Figura 6 tem-se o comportamento da concentração de $\mathrm{NO}_{2}-\mathrm{N}$ e $\mathrm{NO}_{3}-\mathrm{N}$ no efluente tratado e a respectiva eficiência de desnitrificação e de remoção de nitrogênio total. Durante o tempo em que o reator foi operado em ciclos de $3 \mathrm{~h}$, a formação de $\mathrm{NO}_{2}^{-}-\mathrm{Ne} \mathrm{NO}_{3}-\mathrm{N}$ foi baixa (valores médios de 3,6 e 4,4 mg. $\mathrm{L}^{-1}$, respectivamente), tendo em vista a baixa eficiência do processo de nitrificação durante este período (Figura 5). Além disso, parte do $\mathrm{NO}_{3}-\mathrm{N}$ formado foi convertido a nitrogênio gasoso pelo processo de desnitrificação, com eficiência média de $48 \pm 12 \%$. A ocorrência da NDS, mesmo sob condições aeróbias, pode ter sido devida à presença de microrganismos desnitrificantes aeróbios (JU, HUANG; TRIVEDI., 2007), uma vez que os grânulos ainda estavam em processo de formação (Figura 2), o que diminui a probabilidade de existência de micro zonas anóxicas no interior dos mesmos durante esse período. Entretanto, não foi possível efetuar nenhuma análise de identificação microbiológica para comprovar a presença desses microrganismos nos grânulos.

Operando o reator com ciclos de $4 \mathrm{~h}$, houve um aumento na concentração de $\mathrm{NO}_{2}^{-}-\mathrm{Ne} \mathrm{NO}_{3}^{-}-\mathrm{N}$ no efluente (valores médios de 9,7 e 9,3 mg.L.-1, respectivamente), devido ao aumento da eficiência do processo de nitrificação observado durante esse período. A presença de nitrito no efluente tratado indica que o processo de nitrificação não ocorreu até seu último estágio de oxidação (nitratação). Além disso, a eficiência média de desnitrificação aumentou para $64 \pm 14 \%$, sendo que as maiores eficiências (em torno de $80 \%$ ) foram obtidas após 140 dias de operação, o que corresponde ao período em que o processo de granulação no reator estava completo (Figuras 2I e 3). Nesse período, a concentração de nitrito no efluente foi menor (em torno de 4,5 mg. $\mathrm{L}^{-1}$ ), indicando uma melhora na etapa de nitratação. Portanto, a formação de grânulos maduros e densos

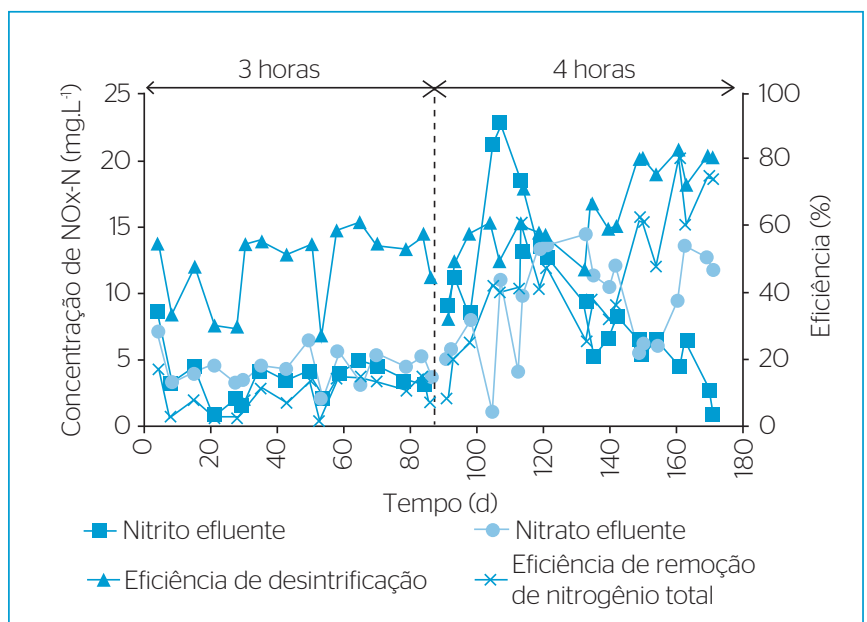

Figura 6 - Comportamento da concentração de $\mathrm{NO}_{2}^{-}-\mathrm{N}$ e $\mathrm{NO}_{3}^{-}-\mathrm{N}$ no efluente tratado, e a respectiva eficiência de desnitrificação e de remoção de nitrogênio total ao longo do tempo de operação.

Tabela 4 - Comparação entre o desempenho de diferentes reatores em bateladas sequenciais de grânulos aeróbios obtidos nos estudos utilizando esgoto doméstico.

\begin{tabular}{|c|c|c|c|c|}
\hline Referência & Afluente & Duração do ciclo (h) & $\begin{array}{c}\text { Eficiência de remoção de } \\
\text { DQO (\%) }\end{array}$ & $\begin{array}{c}\text { Eficiência de remoção de } \\
\qquad \mathrm{NH}_{4}^{+}-\mathrm{N}(\%)\end{array}$ \\
\hline Este estudo & Esgoto doméstico & 4 & $82^{(1)}$ & $69^{(1)}$ \\
\hline Ni et al. (2009) & Esgoto doméstico & $4-3$ & $85-95$ & $90-99$ \\
\hline Liu et al. (2010) & $\begin{array}{c}\text { Esgoto doméstico e } \\
\text { industrial }\end{array}$ & 4 & $80^{(2)}$ & $98^{(2)}$ \\
\hline
\end{tabular}

DQO: demanda química de oxigênio; "valores obtidos após o período de aclimatação (a partir de 50 dias de operação);(2)valores médios. 
pode ter contribuído para a existência de micro zonas anóxicas e, consequentemente, para a maior eficiência do processo de NDS.

Em relação à remoção de nitrogênio total $\left(\mathrm{NH}_{4}{ }^{+}-\mathrm{N}^{-} \mathrm{NO}_{\mathrm{x}}-\mathrm{N}\right)$, observa-se que a mesma foi fortemente afetada pela duração do ciclo. Contudo, mesmo com o aumento do ciclo, a remoção de nitrogênio total foi baixa (média de 46\%). É possível observar ainda que os maiores valores de eficiência de remoção (em torno de 66\%) foram obtidos após 140 dias de operação, devido à melhor eficiência do processo de NDS durante esse período. De acordo com De Kreuk \& Bruin (2004), grânulos aeróbios cultivados em concentrações de OD próximas a saturação, como no caso do reator em estudo, apresentam elevada capacidade de remoção de $\mathrm{DQO}$ e $\mathrm{NH}_{4}{ }^{+}-\mathrm{N}$, mas, por outro lado, a capacidade de remoção de nitrogênio total é insuficiente. Isso ocorre pois em concentrações de OD próximas à saturação, há uma maior penetração do OD no interior dos grânulos, diminuindo o tamanho da zona anóxica e, consequentemente, a eficiência do processo de desnitrificação.

$\mathrm{O}$ comportamento da concentração de $\mathrm{PO}_{4}^{3}$-P afluente e efluente e a respectiva eficiência de remoção ao longo do tempo de operação estão apresentados na Figura 7. Pode-se perceber que houve uma grande oscilação na remoção de fosfato. Para os ciclos de $3 \mathrm{~h}$, a eficiência média de remoção foi de $17 \pm 8 \%$ e a concentração média de $\mathrm{PO}_{4}^{3-}$-P no efluente foi de $8,2 \mathrm{mg} . \mathrm{L}^{-1}$. Já para os ciclos de $4 \mathrm{~h}$, a eficiência média de remoção aumentou para $30 \pm 10 \%$ e a concentração média de $\mathrm{PO}_{4}^{3-}-\mathrm{P}$ no efluente diminuiu para 6,9 mg.L-1.1.

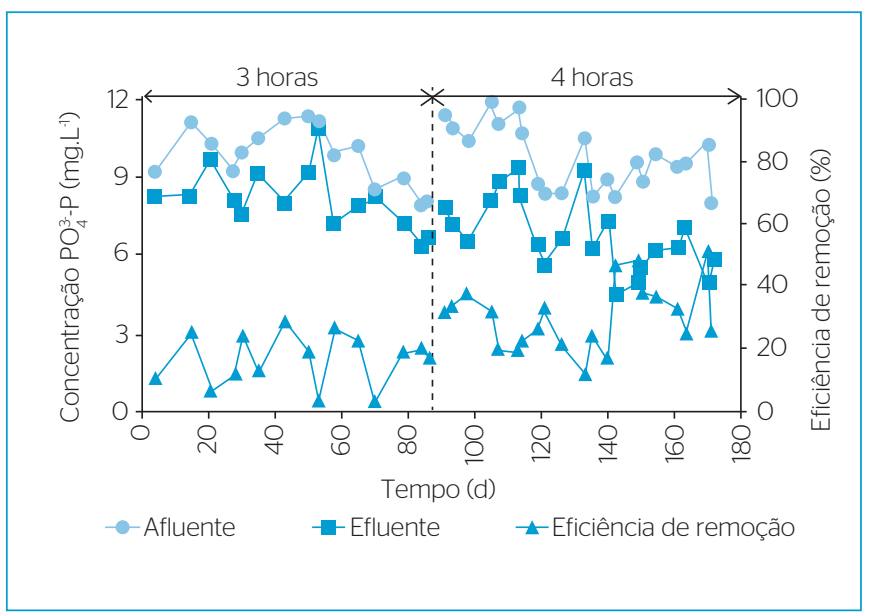

Figura 7 - Comportamento da concentração de $\mathrm{PO}_{4}^{3}-\mathrm{P}$ afluente e efluente e a respectiva eficiência de remoção ao longo da estratégia I.
O desempenho do RBSG na remoção de $\mathrm{PO}_{4}^{3-}-\mathrm{P}$ foi um pouco mais acentuado após 140 dias de operação ( 38\%), o que corresponde ao período em que o processo de granulação no reator estava completo (Figuras 2I e 3). Dessa forma, pode-se concluir que a formação de grânulos maduros e densos contribuiu para a existência de micro zonas anaeróbias e, consequentemente, para a maior eficiência na remoção de $\mathrm{PO}_{4}^{3--}$. Zhu, Liu e Wilderer (2005) também observaram uma melhora na remoção de fósforo com a evolução do processo de granulação. Os autores obtiveram eficiências médias de $60 \%$ quando a biomassa era composta principalmente por flocos, aumentando gradualmente para 67 a $87 \%$ com o aumento da fração de grânulos, e atingindo $99 \%$ após a completa formação dos grânulos no reator.

\section{CONCLUSÕES}

Os resultados mostraram que os grânulos aeróbios podem ser cultivados em um reator em bateladas sequenciais utilizando esgoto doméstico de média concentração (em termos de $\mathrm{DQO}_{\mathrm{S}}$ ). No entanto, o processo de formação desses grânulos demandou bastante tempo (em torno de $150 \mathrm{~d}$ ), o que pode ser ainda um obstáculo para a aplicação prática dessa tecnologia. Dessa forma, o próximo passo é realizar estudos buscando possíveis maneiras para diminuir o tempo necessário para a granulação aeróbia com esgoto doméstico.

Referente ao desempenho do reator, o mesmo apresentou elevada remoção de $\mathrm{DQO}_{\mathrm{s}}$ e $\mathrm{NH}_{4}{ }^{+} \mathrm{N}$, principalmente quando operado em sucessivos ciclos de $4 \mathrm{~h}$. O aumento da duração do ciclo não afetou as características dos grânulos, mas influenciou fortemente a capacidade de remoção de nitrogênio, visto que nessas condições houve uma diminuição da frequência com que os sólidos foram "lavados" do reator, possibilitando, assim, o acúmulo e o crescimento dos organismos nitrificantes. Mesmo com concentrações de OD próximas à saturação, 0 reator removeu fósforo e apresentou atividades desnitrificantes, devido à existência de micro zonas anóxicas e anaeróbias dentro dos grânulos. Entretanto, para uma remoção mais completa desses compostos seria necessário ainda incluir fases anóxicas e/ou anaeróbias durante o ciclo.

De maneira geral, o RBSG mostrou-se capaz de remover carbono, nitrogênio e fósforo em uma única unidade operacional compacta, sendo uma tecnologia bastante promissora para o tratamento de esgoto doméstico. Além disso, a duração do ciclo não foi um parâmetro decisivo no processo de granulação aeróbia, mas influenciou na qualidade do efluente tratado.

\section{REFERÊNCIAS}

APHA - AMERICAN PUBLIC HEALTH ASSOCIATION. (2005) Standard methods for the examination of water and wastewater. 21 ed. Washington: APHA/AWWA/wef.
BERNET, N. \& SPéRANDIO, M. (2009) Principles of nitrifying processes. In: CERVANTES, F.J. (Ed.). Environmental Technologies to Treat Nitrogen Pollution: principles and engineering. London: IWA Publishing. p. 23-39. 
DE KREUK, M.K. (2006) Aerobic granular sludge scaling upanew technology. Tese (doutorado). Delft University of Technology, Delft, The Netherland.

De Kreuk, M.K. \& DE Bruin, L.M.M. (2004) Aerobic granule reactor technology. Water and Wastewater Practioner Series, STOWA Report. London: IWA Publishing.

De Kreuk, M.K. \& Van Loosdrecht, M.C. (2006) Formation of aerobic granules with domestic sewage. Journal of Environmental Engineering, v. 132, n. 6, p. 694-697.

De Kreuk, M.K.; McSwain, B.S.; Bathe, S.; Tay, S.T.L.; Schwarzenbeck, N.; Wilderer, P.A. (2005) Discussion outcomes. In: Aerobic granular sludge. Water and Environmental Management Series. London: IWA Publishing, p. 155-169.

FIGUEROA, M.; VAL DEL RIO, A.; MORALES, N.; CAMPOS, J.L.; MOSQUERA-CORRAL, A.; MENDEZ, R. (2009) Nitrogen removal in aerobic granular systems. In: CERVANTES, F.J. (Ed.). Environmental Technologies to Treat Nitrogen Pollution: principles and engineering. London: IWA Publishing. p. 373-401.

JU, L.K.; HUANG, L.; TRIVEDI, H. (2007) Simultaneous nitrification, denitrification, and phosphorus removal in single-tank low-dissolvedoxygen systems under cyclic aeration. Water Environment Research, v. 79 , n. 8, p. 912-920

JUNGLES, M.K.; FIGUEROA, M.; MORALES, N.; VAL DEL RIO, A.; COSTA, R.H.R:; CAMPOS, J.L.; MOSQUERA-CORRAL, A.; MÉNDEZ, R. (2O11) Start up of a pilot scale aerobic granular reactor for organic matter and nitrogen removal. Journal of Chemical Technology \& Biotechnology, v. 86, n. 5, p. 763-768.

Li, X.M.; Yang, G.J.; Zeng, G.M.; Liao, D.X.; Hu, M.F.; Wu, Y.M. (2005) Simultaneous phosphorus and nitrogen removal by aerobic granular sludge in single SBR system. In: Aerobic Granular Sludge. Water and Environmental Management Series. London: IWA Publishing. p. 71-78.

LIU, Y.Q.; MOY, B.Y.P.; TAY J.H. (2007) COD removal and nitrification of lowstrength domestic wastewater in aerobic granular sludge sequencing batch reactors. Enzyme and Microbial Technology, v. 42, n. 1, p. 23-28.

LIU, Y.Q.; MOY, B.; KONG, Y.H.; TAY, J.H. (2O10) Formation, physical characteristics and microbial community structure of aerobic granules in a pilot-scale sequencing batch reactor for real wastewater treatment. Enzyme and Microbial Technology, v. 46, n. 6, p. 520-525.

LIU, Y.Q. \& TAY, J.H. (2004) State of the art of biogranulation technology for wastewater treatment. Biotechnology Advances, v. 22, n.7, p. 533-563.

LIU, Y.Q. \& TAY, J.H. (2006) Variable aeration in sequencing batch reactor with aerobic granular sludge. Journal of Biotechnology, v. 124, n. 2, p. 338-346.

LIU, Y.Q. \& TAY, J.H. (2007a) Influence of cycle time on kinetic behaviors of steady-state aerobic granules in sequencing batch reactors. Enzyme and Microbial Technology, v. 41, n. 4, p. 516-522.

LIU, Y.Q. \& TAY, J.H. (2007b) Characteristics and stability of aerobic granules cultivated with different starvation time. Applied Microbiology and Biotechnology, v. 75, n.1, p. 205-210.

MCSWAIN STURM, B.S. \& IRVINE, R.L. (2008) Dissolved oxygen as a key parameter to aerobic granule formation. Water Science \& Technology, v. 58, n. 4 , p. $781-787$
METCALF \& EDDY Inc. (2003) Wastewater engineering: treatment disposal, and reuse. 4 ed. New York: McGraw-Hill. 1819 p.

MORGENROTH, E.; SHERDEN, T.; VAN LOOSDRECHT, M.C.M.; HEIJNEN, J.J.; WILDERER, P.A. (1997) Aerobic granular sludge in a sequencing batch reactor. Water Research, v. 31, n. 12, p. 3191-3194.

Ni, B.J.; Xie, W.M.; Liu, S.G.; Yu, H.Q.; Wang, Y.Z.; Wang, G.; Dai, X.L. (2009) Granulation of activated sludge in a pilot-scale sequencing batch reactor for the treatment of low-strength municipal wastewater. Water Research, v. 43, n. 3, p. 751-761.

PIJUAN, M.; WERNER, U.; YUAN, Z. (2O11) Reducing the startup time of aerobic granular sludge reactors through seeding floccular sludge with crushed aerobic granules. Water Research, v. 45, n. 16, p. 5075-5083.

SANT'ANNA JR., G.L. (2010) Tratamento biológico de efluentes: fundamentos e aplicações. Rio de Janeiro: Interciência, 398 p.

SCHWARZENBECK, N.; BORGES, J.M.; WILDERER, P.A. (2005) Treatment of dairy effluents in an aerobic granular sludge sequencing batch reactor. Applied Microbiology and Biotechnology, v. 66, n. 6, p. 711-718.

SCHWARZENBECK, N.; ERLEY, R.; WILDERER, P.A. (2004) Aerobic granular sludge in an SBR-system treating wastewater rich in particulate matter. Water Science and Technology, v. 49, n. 11-12, p. 41-46.

TAY, J.H.; YANG, S.F.; LIU, Y. (2002) Hydraulic selection pressureinduced nitrifying granulation in sequencing batch reactors. Applied Microbiology and Biotechnology, v. 59, n. 2-3, p. 332-337.

USEPA - UNITED STATES ENVIRONMENTAL PROTECTION AGENCY (2010) Nutrient control design manual. EPA/600/R-10/100. Washington, DC

Von SPERLING, M. (2002) Lodos Ativados: princípios do tratamento biológico de águas residuárias. v. 4.2 ed. Belo Horizonte: Departamento de Engenharia Sanitária e Ambiental; Universidade de Minas Gerais. 428 p.

WAGNER, J. \& COSTA, R.H.R. (2013) Aerobic granulation in a sequencing batch reactor using real domestic wastewater. Journal of Environmental Engineering, v. 139, p. 1391-1396.

WANG, F.; LU, S.; WEI, Y.; JI, M. (2009) Characteristics of aerobic granule and nitrogen and phosphorus removal in a SBR. Journal of Hazardous Materials, v. 164, n. 2-3, p. 1223-1227.

WANG, F.; YANG, F.L.; ZHANG, X.W.; LIU, Y.H.; ZHANG, H.M.; ZHOU, J. (2005) Effects of cycle time on properties of aerobic granules in sequencing batch airlift reactor. World Journal of Microbiology \& Biotechnology, v. 21, n. 8-9, p. 1379-1384

WANG, S.G.; LIU, X.W.; ZHANG, H.Y.; GONG, W.X.; SUN, X.F.; GAO, B.Y (2007) Aerobic granulation for 2,4-dichlorophenol biodegradation in a sequencing batch reactor. Chemosphere, v. 69, p. 769-775.

WANG, Z.W. \& LIU, Y. (2008) Aerobic granulation at different SBR cycle times. In: LIU, Y. (Ed.). Wastewater purification: aerobic granulation in sequencing batch reactors. Boca Raton: CRC Press. p. 37-67.

ZHU, J.; LIU, C.; WILDERER, P.A. (2005) Bio-P removal profile of aerobic granular activated sludge from an anaerobic/aerobic SBR system. In: Aerobic granular sludge. Water and Environmental Management Series. London: IWA Publishing. p. 79-86. 